\title{
EL ESTADO DE EXCEPCIÓN COMO MILAGRO: DE DONOSO A BENJAMIN
}

JUAN MAYORGA

Dpto. de Filosofía y Filosofía moral. UNED

Es sabido que Donoso utilizó en 1849 la analogía entre el milagro como fenómeno excepcional en la naturaleza y la dictaduracomo situación excepcional en el Estado, para probar que circunstancias excepcionales exigen decisiones excepcionales ${ }^{1}$. Mucho menos conocido es que ya en 1837 el aún liberal Donoso había defendido lo esencial de esa teoría ${ }^{2}$. Merece la pena comprobar que, entre ambos momentos, la teologización del pensamiento de Donoso crece paralela al miedo de los propietarios hacia la revolución. Lo que no es insignificante para establecerla relación entre teología y política. La continuidad del pensamiento donosiano en la vinculación a los intereses de una clase, muestra además que "estado de excepción" puede ser lo contrario de "interrupción".

Al recuperar la analogía donosiana, Schmitt captó que lo milagroso no residía en la dictadura misma, sino en la rupturade la continuidad jurídica ${ }^{3}$. Para él, «el estado excepcional tiene en la Jurisprudencia análoga significación que el milagro en la Teología"t. Pero la posición de Schmitt no debe ser confundida con la

\footnotetext{
${ }^{1}$ Juan Donoso Cortés, Obras completas, ed. Carlos Valverde, Vol I-II, Madrid 1970, Vol. II, p. 309 . En lo sucesivo, sólo citaré volumen y página.

${ }^{2}$ Donoso I, 389.

${ }^{3}$ Carl Schmitt, La Dictadura, ed. José Díaz García, Madrid 1968, p. 184.

${ }^{4}$ Carl Schmitt, Politische Theologie, Vier Kapitel zur Lehre von der Souveranität, 5.ed., Berlin 1990, p. 49. Me servire de la versión española: Carl Schmitt, Estudios políticos, Madrid 1975.
}

Éndoxa: Series Filosóficas, $n^{\circ} 2,1993$, UNED, Madrid:

Juan Mayorga: El estado de excepción como milagro: de Donoso a Benjamin pp.283-301 
de Donoso, a quien un ideal absoluto dejusticia aparta del decisionismo puro. En Schmitt, el estado de excepción suspende el Derecho para conservar el Estado; en Donoso, realiza justicia más allá del Derecho. En Benjamin, en cambio, ha de ser realización de la justicia en la interrupción del capitalismo. La fractura de la continuidad jurídica no aparece aquí en la dictadura, sino como entusiasmo en la expectativa de un orden distinto. La expectativa de huelga general, tal como la describió Sorel, sirve de modelo a un "verdadero estado de excepción" ${ }^{\text {"5 }}$. Dictadura y huelga general son tan opuestos como los contenidos con que Donoso y Benjamin saturan la fórmula "Contra catástrofe, estado de excepción". Pues en el católico Donoso, el estado de excepción defiende el continuo frente a la catástrofe, mientras que en el judío Benjamin interrumpe la continua catástrofe. Dos teologias -una de la encarnación, otra de la esperanza en la desesperación- orientan dos políticas -la que defiende el orden establecido por Dios y la que busca en el orden la puerta por que entrará el Mesias-. Más allá del Derecho, vive en ambas la justicia. Absoluta o Absolutamente Otra.

\section{El juicio de Dios}

En la sexta de sus «Lecciones de Derecho Político", mucho antes de su conversión política y religiosa, el entonces liberal Donoso justificó la dictadura en el caso excepcional. «Cuando los que obedecen se insurreccionan contra los que mandan $[. .$.$] , ¿no será$ necesaria la omnipotencia para que se salve a la sociedad entera conmovida en sus cimientos?"16 ${ }^{\prime \prime}$ se pregunta, y diagnostica que «sin duda un poder omnipotente es entonces necesario para que pueda decir a la revolución como Dios a la mar embravecida: «No pasarás de aquí..."'t7. No es fácil al joven liberal encontrar ese poder omnipotente "porque cuando las revoluciones aparecen, las Constituciones pasan, los pueblos pasan, los reyes pasan, y en

\footnotetext{
${ }^{5}$ Donoso I, 327-445.

${ }^{6}$ Donoso I, 389.

${ }^{7}$ Donoso I, 390.
} 
lugar de las Constituciones, de los reyes y de los pueblos, que se retiran de la escena, invade la escena el caos" ${ }^{\prime 8}$. Sólo acierta a situarlo «en el hombre fuerte e inteligente que las Constituciones no adivinan, y que el destino reserva ignorado de sí propio e ignorado de los pueblos, para oponer sus hombros de Hércules al grave peso del edificio que cae, de la sociedad que se desploma; en el hombre fuerte e inteligente, que aparece como una divinidad, y a cuya aparición las nubes huyen, el caos informe se anima, el Leviatán que ruge en el circo calla, las tempestades se serenan. Así se forma, así nace, así aparece el poder constituyente; él no pertenece al dominio de las leyes escritas, no pertenece al dominio de las teorías filosóficas; es una protesta contra aquellas leyes y contra estas teorias't.

En esta caracterización del poder constituyente como «excepción terrible» que "no cabe en los libros y rompe el cuadro de las constituciones ${ }^{10}$ aparecen ya temas fundamentales del Donoso reaccionario: la defensa de la sociedad frentè a la revolución, la crisis de la legitimidad monárquica, la incapacidad de la ley para prever la respuesta al caso excepcional. Aparece, sobre todo, la analogia entre el "hombre fuerte" y Dios. Como en el «Discurso de la Dictadura"de $1849^{11}$, distinguiré dos aspectos que encierra, en mi opinión, esta analogía:

a) La acción del dictador tiene, en lo jurídico, el mismo significado que el milagro en lo teológico.

b) El dictador, que «aparece como una divinidad", encarna un ideal absoluto de justicia más allá del Derecho.

A pie de página, Donoso matizó que «el poder constituyente, colocado en una sola mano en medio de una crisis social, no es una excepción, es una confirmación del principio de la soberanía

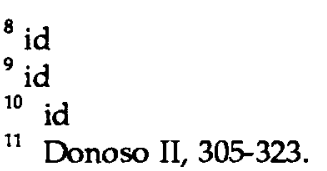


de la inteligencia"12. El significado de "inteligencia" es tan central en el primer Donoso como lo es el de "verdad" en el segundo. El camino teologizante de la inteligencia a la verdad corresponde a un cambio de enemigo.

El Donoso liberal -el de las «Lecciones» y las «Consideraciones sobre la Diplomacia"- adoptó la bandera de la soberanía de la inteligencia (a la que asoció el proyecto político de una monarquía apoyada sobre las clases medias propietarias) frente a la del derecho divino de los reyes (esto es: frente al Antiguo Régimen) y a la de la soberanía popular.

Los sucesos revolucionarios de 1830 y 1835 mostraron una tensión entre libertad y orden, que se resuelve en las «Lecciones» con un concepto de gobierno como arma defensiva de lo que Donoso llama «la sociedad": «El hombre, absolutamente libre, destruiría la sociedad que su inteligencia ha hecho necesaria, porque la libertad es por su naturaleza un principio disolvente de toda asociación. La sociedad necesita, pues, de un arma para defenderse contra el principio que la invade; este arma es el Gobierno. El Gobierno no gobierna sino obrando porque, como he dicho antes, para el Gobierno obrar es ser, y no obra sino resistiendo al principio invasor; por consiguiente, para el Gobierno obrar es resistir. Si el Gobierno es una acción, y esta acción es una resistencia, el Gobierno es una resistencia también ${ }^{13}$. El índice liberal de este programa se hace más nítído en la afirmación de que tal resistencia no es indefinida: «siendo su objeto defender a la sociedad de las invasiones de la individualidad humana, su acción no debe extenderse más de lo que sea necesario para evitar semejantes invasiones"14 $^{114}$ La justicia, límite del gobierno, eexige la conservación simultánea de la sociedad y de la libertad del hombre" ${ }^{\prime 15}$.

Donoso I, 391

Donoso I, 333.

Donoso I, 333ss.

Donoso I, 334. 
Para nosotros va a ser central el paso de esa noción liberal de justicia a otra, católica, en que la palabra "libertad" desaparece.

La misión del gobierno de conservar la sociedad exige capacidad para prever obstáculos, es decir, inteligencia. Tal es la fórmula del optimista liberal, que habla con desdén de aquellos que «abrieron sus ojos a la luz para presenciar catástrofes y para medir abismos ${ }^{16}$. La inflexión catastrofista será paralela en Donoso a la autoritaria, pues ambas reflejan el creciente desorden social. En 1838 , Donoso sustituye "inteligencia" por "verdad", y achaca a la falta de conciencia de poseer ésta la división en el liberalismo ${ }^{17}$. Firme en su objetivo, que sigue siendo la perpetuación de "la sociedad", Donoso da cada vez más importancia a la religión como base social ${ }^{18}$. La verdad religiosa aparece como «única que puede servir de indestructible fundamento a las sociedades humanas" ${ }^{19}$ contra el desorden. Donoso fue racionalista hasta que supo que el racionalismo no frenaría las revoluciones. Frente a éstas -el fruto más dañino de la secularización- sólo sería fuerte el catolicismo, civilización completa y garante de paz social, que «puede reconocer sin injusticia la desigualdad entre los hombres, porque les ofrece la igualdad en el cielo"20. La solidaridad del pensamiento donosiano con los intereses de una clase queda al descubierto en lo que su editor califica como «una de las características oscilaciones de todo proceso psicológico humano" ${ }^{21}$ y que yo interpreto de otro modo. Se trata del debate sobre la expropiación de que las órdenes religiosas habian sido víctimas en 1835. Allí, Donoso proclama que, aún cuando las revoluciones son el crimen por excelencia, satánicas, introducen cosas positivas en la historia, lo que las hace providenciales ${ }^{22}$. Más tarde añade que la propiedad

\footnotetext{
${ }^{16}$ Donoso I, 445.

7 Donoso I, 521 ss.

18 Especialmente desde "De la monarquía absoluta en España". Donoso I, 526-580.

19 Donoso I, 653.

20 Donoso II, 25.

21 Donoso II, 94.

22 Donoso II, 95.
} 
de los bienes eclesiásticos no es, como la de los particulares, inviolable $^{23}$. ¿Giro a la izquierda de Donoso? Más bien, continuidad en el apoyo de los propietarios.

Defensa de "la sociedad", tal fue el motivo común del Donoso liberal y del que anhelaba la reconstrucción del orden cristiano. La tensión libertad/excepcionalidad de la lección VI se ha hecho, diez años más tarde, filosofía de la historia: «La Historia, considerada en general, es la narración de los acontecimientos que manifiestan los designios de Dios sobre la Humanidad y su realización en el tiempo, ya por medio de su intervención directa y milagrosa, ya por medio de la libertad del hombre" ${ }^{124}$. Su corolario político es el "Discurso de la Dictadura". La "sociedad" es parte de los designios de Dios, y éstos han de realizarse, aunque sea milagrosamente. Ante el desorden, el teólogo concentra el dominio en un solo sable, como el racionalista lo concentró en un solo cerebro. "Derecho común para tiempos buenos, derecho excepcional para tiempos excepcionales", era ya lema en el joven Donoso ${ }^{25}$. La salvación de "la sociedad" era prioritaria a la defensa de cualquier derecho para un Donoso convencido -!ya en 1839 !- «de que, cuando se disuelven los vínculos sociales, naufragan todos los derechos en un naufragio común; de que la acción social tiende siempre a reconcentrarse cuando la sociedad tiende a disolverse; de que cuando la fuerza loca y desatenta se burla de la mansedumbre de la ley, la ley debe buscar a su vez el omnipotente amparo de la fuerza; y de que, si la ley no le buscara, la sociedad le buscaría en el momento del peligro"26.

No cambia el objetivo político. Cambia el tamaño del enemigo democrático. Con la amenaza de éste, crece la desconfianza en el racionalismo y en su escenario, el parlamento restringido, que de espacio de la discusión inteligente pasa a teatro de la indecisión.

Donoso I, 712.

Donoso I, 718. 
El pesimismo ante la época se hace perspectiva que unifica la historia bajo una sola forma: la victoria irresistible del mal y su derrota por la acción directa, personal y soberana de Dios.

Lo que aclara, pero no agota, el significado de una conversión que, según el propio Donoso, se debía «en primer lugar, a la misericordia divina, y después, al estudio profundo de las revoluciones" ${ }^{\prime 27}$. Asociar el pensamiento de Donoso a los intereses de las nuevas clases propietarias, ayuda a entender tanto la evolución donosiana como sus vacilaciones. Pero sería falsificador reducir a Donoso al papel de intelectual orgánico de una clase a la que fueron funcionales, antes, el liberalismo oligárquico, y después, la sacralización del poder ${ }^{28}$.

Para el último Donoso, el catolicismo es una civilización completa $^{29}$. "Secularización» significaba derrota no sólo de la obediencia, sino también de la caridad ${ }^{30}$. Cierto que el catolicismo santifica la autoridad ${ }^{31}$, pero también es incompatible con el despotismo, pues hizo a los gobernadores «ministros de Dios y servidores de los pueblos"32. "Cuando el hombre llegó a ser hijo de Dios, luego al punto dejó de ser esclavo del hombre"33: tal pensamiento es central en este Donoso en que se afirma un ideal católico de justicia. De ahí la distancia con que habla de las clases burguesas, que han olvidado la cristiana virtud de la caridad ${ }^{34}$, solución del problema de distribución de la riqueza ${ }^{35}$.

El primer Donoso ofreció una definición iusnaturalista de

Donoso II, 327.

28 cf. Jesús Alvarez Junco, Estudio preliminar, en: Lecciones de derecho político, Juan Donoso Cortés, Madrid 1984, pp. 9-37, p. 27. Este interesante trabajo bordea siempre el tipo de reducción de que hablo.

Donoso II, 492 s.

Donoso II, 464s.

Donoso II, 525.

Donoso II, 510.

id.

34 Donoso II, 724.

${ }^{35}$ Op.cit. Vol I p. 429 s. 
legitimidad del soberano como «la conformidad de sus acciones públicas con la justicia, que, si bien es siempre una, no por eso deja de ser diversa en su aplicación a las sociedades modificadas por los siglos. En cada época de la Historia la justicia está representada por el principio llamado a la dominación, que es la expresión viviente de la armonía entre el derecho absoluto y las necesidades sociales" ${ }^{136}$. Esta definición no se adecúa menos a la postura del segundo Donoso, en que justicia y orden divino se hacen inseparables. "Caridad", "amor", "justicia", no eran sólo palabras para el Donoso que, en 1849, comparó dictadura y milagro. Cualquier interpretación que ignore esto es insuficiente.

II. El juicio de los fuertes

El pensamiento reaccionario del siglo $X X$ no ha desperdiciado las enseñanzas de sus antecedentes católicos del XIX. Carl Schmitt encontró en Donoso dos percepciones fundamentales: 1) El liberalismo es un débil enemigo del socialismo; 2) dado que la restauración es imposible, sólo la dictadura puede contener a las revoluciones. Con enorme agudeza, Schmitt captó el nudo de la analogía "milagro-estado de excepción": "Se ha dicho de la dictadura que es un milagro, con lo cual se fundamenta el que la suspensión de las leyes sea comparada a la suspensión de las leyes naturales. En realidad, este milagro no lo constituye la dictadura, sino la ruptura de la continuidad jurídica que implica tal dominación recién establecida" ${ }^{\prime 37}$.

La doctrina de Schmitt no estaba menos vinculada que la de Donoso a los intereses de una clase. Maus me ha convencido de que el decisionismo schmittiano es útil a la economía capitalista en una fase de su desarrollo en que necesita la intervención del

Donoso I, 264.

${ }^{37}$ Schmitt, La Dictadura (Nota 3) p. 184. 
estado y la teme en su virtualidad democratizadora ${ }^{38}$. Un ejecutivo independiente frente a las instituciones liberales -cuyo control estaba perdiendo la burguesía- tal como Schmitt lo diseña, atiende a esa necesidad y decide el enfrentamiento político. La inadecuación de constitución y parlamento a la economía moderna y la fidelidad a la lógica Base-Superestructura, decidieron -siempre según Maus- a la industria alemana por su emancipación respecto del derecho y por la dictadura ${ }^{39}$.

La schmittiana "Revolución permanente del Derecho» ${ }^{40}$ sirve de arma a una economía en crisis frecuente. Un «Führer sin Constitución", además de frenar al enemigo revolucionario, parece más adecuado que el Derecho escrito ante una realidad en que la excepción se ha vuelto cotidiana e imprevisible. El "estado de excepción" se hace así defensa del continuo. Permite, sin embargo, presentar al estado decisionista (que es "estado máximo «ante el revoltoso y «estado mínimo» ante el capital) como interrupción de la Historia.

La contextualización de Donoso y de Schmitt como «guardianes del continuo" no ha de ocultar la fundamental diferencia entre ambos. La reducción schmittiana de Donoso al elemento decisiónignora el ideal de justicia que subyace al español. Tal ideal es incompatible con la dictadura de Schmitt en cuanto «reducción del Estado al factor decisión; consecuentemente, a una decisión pura, que no razona ni discute ni se justifica, es decir, creada de la nada y absoluta"41. Es coherente en cambio con el discurso del 30 de diciembre de 1850 en que, por razones de justicia, Donoso derriba

\footnotetext{
${ }^{38}$ Ingeborg Maus, Rechtstheorie und Politische Theorie im Industriekapitalismus, München 1986; cf. Bernd Rüthers, Carl Schmitt im Dritten Reich, Wissenschaft als Zeitgeistverstärkung?, München 1989, p. 102s. Rüthers no ha captado lo que de vigente tiene el pensamiento schmittiano.

${ }_{30}$ Maus, Rechtstheorie und Politische Theorie idustriekapitalismus (Nota 38) p. 155.

${ }^{40}$ De nuevo, la expresión es de Maus. Op. cit. p. 159.

${ }^{41}$ Carl Schmitt, Donoso Cortés in gesamteuropäischer Interpretation, Vier Aufsätze, Köln 1950, p. 39s. Utilizaré la versión española: Carl Schmitt, Interpretación europea de Donoso Cortés, 2. ed., Madrid 1963.
} 
a Narváez, el mismo general al que dos años antes había apoyado en el «Discurso de la Dictadura".

Entre Donoso y Schmitt media un siglo en que la idea de soberanía popular se impone $e^{42}$. Si Donoso fundó la legitimación de la dictadura sobre una noción de "justicia absoluta", Schmitt quiere justificarla conforme al principio democrático, lo que le lleva a defender la teoría del caudillo aclamado por el pueblo frente a la teoría de la representación. Esto supone un vaciamiento de la analogía «milagro-estado de excepción", que queda reducida a forma.

En realidad, toda la Teología Política pierde su contenido religioso. La «Ciencia que trata de Dios» es desplazada por Schmitt a un mundo sin Dios. En ese sentido hay que leer la fórmula «todos los conceptos sobresalientes de la moderna teoría del Estado son conceptos teológicos secularizados" ${ }^{\prime 43}$. Tales conceptos, junto a su estructura sistemática, habrian viajado de la teología a la teoría del estado. En particular, «el estado de excepción tiene en la Jurisprudencia análoga significación que el milagro en la Teología" 44 . Nos encontramos ante una mera correspondencia formal. «El modo teológico de Donoso está en la línea del pensamiento medieval, cuya estructura es jurídica.

[...] La actitud científica naturalista del siglo XIX es para Donoso ininteligible, como ininteligible es para esa actitud científica el decisionismo y el rigor lógico específico de un pensamiento que culmina en una decisión personal" ${ }^{145}$ : esta afirmación supone un olvido de los valores católicos que defiende el Donoso del "Ensayo", aquél que Schmitt despreciaba como profano metido a teologías ${ }^{46}$.

42 cf. Gonzalo Fernández de la Mora, Schmitt y Donoso ante la dictadura, en: Razón española 17 (1986) pp. 311-322, p. 321.

${ }^{43}$ Schmitt, Politische Theologie (Nota 4) p. 49.

${ }^{44}$ Id.

${ }^{45}$ Op. cit. p. 66.

${ }^{46}$ Schmitt, Donoso Cortés in gesamteuropäischer Interpretation (Nota 41) p. 69s. 
Lo político, cuando se orienta a un ideal de justicia, reproduce lo teológico no sólo en cuanto forma. Schmitt estuvo cerca de reconocer otra dimensión de la correspondencia «milagro-estado de excepción". Con razón contrapone a Donoso con Sorel: «Llega el día de las negaciones radicales o de las afirmaciones soberanas"; ninguna discusión parlamentaria podrá frenarlo; el pueblo, empujado por sus instintos, romperá las cátedras de los sofistas. Todas estas observaciones de Cortés podrian proceder, palabra por palabra, de Sorel, salvo que el anarquista se halla de parte de los instintos del pueblo"47. Cuando, creyendo parafrasear una previsión de Donoso, escribe que entre los dos enemigos del liberalismo, a la izquierda y a la derecha, «las contradicciones alcanzarían de nuevo dimensiones espirituales y una tensión realmente escatológica"48, no está presentando lo teológico como análogo estructural, sino como intensidad extrema.

Donoso y Sorel representan dos «instintos" ${ }^{49}-\mathrm{a}$ ambos lados del liberalismo, incapaz de "instinto"- de cuyo choque resulta lo teológico. En la "contradicción directa e intuitiva de las imágenes míticas ${ }^{50}$ se funda esa tensión teológica.

Sorel había desarrollado la teoría de los mitos sociales, que presentó así: "Los hombres que toman parte en los grandes movimientos sociales se imaginan su acción inmediata en forma de batallas que conducen al triunfo de su causa. Proponía yo denominar mitos a esas construcciones" ${ }^{\prime 51}$. Se trata de «imágenes capaces de evocar, en conjunto y por mera intuición, antes que cualquier análisis reflexivo, la masa de los sentimientos" ${ }^{152}$. El

47 Carl Schmitt, Die geistesgeschichtliche Lage des heutigen Parlamentarismus, 2. ed., München und Leipzig 1926, p. 82. Me serviré de la traducción de Thies Nelsson y Rosa Grueso: Carl Schmitt, Sobre el parlamentarismo, Madrid 1990.

48 id

49 id

50 id

51 Georges Sorel, Réflexions sur la violence, 11. Aufl., Paris 1950, p. 32. Voy a utilizar la traducción de Florentino Trapero: Georges Sorel, Reflexiones sobre la violencia, Madrid 1972.

52 Op. cit. p. 173. 
mito, en tanto expresión unitaria de una voluntad colectiva, es opuesto a la utopía que el intelectual compone. Schmitt reconoció la importancia de la teoría soreliana, convencido de que no en la lucha de clases, sino en lo nacional descansan los mitos más fuertes. Se conformó con constatar que «alli donde se ha llegado a un conflicto abierto entre los dos mitos -en Italia- ha vencido, hasta hoy, el mito nacional ${ }^{153}$. Su última observación acerca de los mitos sorelianos desatiende otra vez lo peculiar que en un ideal de justicia ha de reconocer la Teología Política: la pluralidad de mitos le parece politeísmo ${ }^{54}$.

Schmitt no prestó suficiente atención a la importancia jurídica del mito soreliano por excelencia: el de la huelga general. Por eso no descubrió lo teológico en el socialismo de Sorel, sino más bien lo energético. A Benjamin, en cambio, la dimensión mítica del socialismo no le ocultó su lado teológico. Benjamin se dio cuenta de que también la huelga general puede ser un estado de excepción.

III. El juicio de los vencidos

La izquierda tiene su lugar en la Teología Política schmittiana. Según Schmitt, «desde el instante en que los escritores de la Restauración desarrollaron una teología política, la lucha ideológica de los adversarios radicales del orden existente se centró, con conciencia cada vez más clara, en torno a esa creencia en Dios, expresión fundamental y extrema de la fe en el mando y en la unidad"55. Pero ¿por qué no participó Benjamin en esa batalla contra Dios? Tal pregunta formula un problema de la Teología Política.

Que no se puede leer a Benjamin ateológicamente, nos es tan claro como que no se le puede leer teológicamente: «Mi pensa-

53 Schmitt, Die geistesgeschichtliche Lage des heutigen Parlamentarismus (Nota 47) p. 88 .

${ }_{54}$ Op. cit. p. 89

${ }^{55}$ Schmitt, Politische Theologie (Nota 4) p. 63ss. 
miento se relaciona con la teología como el papel secante con la tinta. Está empapado de ella. Pero si se fuese al papel secante, no se encontraría nada de lo que fue escrito" ${ }^{156}$. Con la cautela que semejante afirmación impone, afirmo que la analogía «estado de excepción-milagro" reaparece en Benjamin. $Y$ lo hace saciada de la noción de justicia -ya no "absoluta", como en Donoso, sino "absolutamente otra"- que en Schmitt se había perdido.

Una «tormenta irresistible» es el lugar poético en que Donoso y Benjamin coinciden. La "Lección VI» describe así el caso excepcional: "Cuando esa mar borrascosa a que se llama muchedumbre, agitada por recios huracanes, hiere, rompe sus diques, azota los cimientos de los tronos que vacilan e inunda los alcázares de los reyes que naufragan; cuando el poder constituido y limitado desaparece de la sociedad cual leve arista que arrebata la tormenta $^{1.57}$. La figura de la tempestad no abandonará a Donoso. Pero en el «Ensayo» expresa no ya una excepción, sino la regla de que, si la libertad se entiende como la facultad de escoger, «entre la perfección y la libertad del hombre hay contradicción patente, incompatibilidad absoluta"58. Donoso caracteriza la humanidad como enloquecida tripulación de un buque sin capitán: « $Y$ no saben ni adónde van, ni de dónde vienen, ni cómo se llama el buque que los lleva, ni el viento que los empuja. [...] Y los huracanes arrecian, y el buque comienza a crujir ${ }^{\prime 159}$. ¿Cómo no recordar al Angelus Novus y la tormenta que «desciende del Paraíso y se arremolina en sus alas y es tan fuerte que el ángel no puede plegarlas. [...] Tal tempestad es lo que llamamos progreSo" $^{160}$ ?

\footnotetext{
${ }^{56}$ Citaré los textos de Benjamin refiriéndome al volumen y página correspondiente de: Walter Benjamin, Gesammelte Schriften, Frankfurt 1976. Aquí: Benjamin V/1, 588 .

Donoso I, 388.

Donoso II, 549.

Donoso II 560 .

60 Benjamin I/2, 697s. Hay varias versiones castellanas de las "Tesis". Utilizo la de M. A. Sandoval en: Walter Benjamin, Para una crítica de la violencia, México: 1978.
} 
Si Donoso acabó condenando todos los sistemas de progreso ("Toda mi doctrina está aquí: el triunfo natural del mal sobre el bien y el triunfo sobrenatural de Dios sobre el mal" ${ }^{\prime 61}$ ), para Benjamin el único progreso está en las interferencias de la "acumulación de lo mismo" conocida vulgarmente como "progreso" ${ }^{162}$. Ambos oponen al del progreso el dogma del pecado original. "¿Qué significa "progreso", si Dios habló al primer hombre?", parece ser la pregunta de Donoso ${ }^{63}$. En Benjamin, es la tempestad que llamamos progreso la que aleja al ángel de la historia del paraíso ${ }^{64}$, en que el nombre era creador. Ese progreso es hoy capitalismo, es decir, un culto que no sirve "para expiar en él la culpa, sino para hacerla universal, meterla a la fuerza en la conciencia $y$, por último y sobre todo, abarca a Dios mismo en esa culpa para interesarle a El, al final, en la expiación"65.

Según Benjamin, el capitalismo es una religión que resiste «hasta el final, hasta la culpabilización final de Dios, hasta la obtención de un estado mundial de desesperación por el que precisamente se espera $^{166}$. Nos encontramos ante una teología política negativa que responde a ula expansión de la desesperación a estado religioso mundial del cual ha de esperarse la redención. La trascendencia de Dios se ha derrumbado. Pero Dios no está muerto, está comprendido en el destino humano"67.

Dos teologias, dos políticas. Donoso niega el progreso porque la sociedad proviene de Dios y, por lo tanto, el hombre no puede

61 Donoso II, 337ss.

$62 \mathrm{~V} / 1,593$.

63 Donoso II, 982s. Schmitt relaciona el dogma del carácter pecaminoso del mundo con su distinción entre amigo y enemigo. Carl Schmitt, Der Begriff des Politischen, München und Leipzig 1932, p. 51ss.

${ }_{64}$ Benjamin $I / 2,697 \mathrm{~s}$.

65 Benjamin VI, 100s. Ana Lucas me hizo ver la conexión entre la tesis IX y "Kapitalismus als Religion". Soy deudor de la traducción que de este último texto ha realizado Luis Meana en "Walter Benjamnin en la 'época del infierno", suplemento de El País del 20.9.1990, p. 5.

66 Benjamin VI, 101.

67 id. 
cambiar sus fundamentos. La redención «constituye al hombre en un estado de civilización perfectísimo e incomparable"68. En Donoso, la negación teológica del progreso niega la revolución -que es, como el pecado, una interrupción del orden establecido por Dios: «Las revoluciones son la misma cosa en lo político que en lo moral el pecado" ${ }^{169}$-; en Benjamin la afirma. Pues no se trata de defender el orden establecido por un Dios encarnado, sino de suspender el orden que cierra la puerta al Mesías.

Sólo un milagro puede interrumpir la humanamente irrefrenable tormenta. Frente a catástrofe, estado de excepción. Todo depende de qué se vea como catástrofe y qué como excepción. Qué como Cristo y qué como Anticristo. Lo que, a su vez, es función de la perspectiva que se escoja. Para Donoso, la revolución es la catástrofe, y la defensa del continuo -"la sociedad"-, el estado excepcional. Para Benjamin, en cambio, el continuo es la catástrofe (Tesis VIII: "La tradición de los oprimidos nos enseña entretanto que el «estado de emergencia» en que vivimos es la regla"70 y la revolución la excepción. Porque Benjamin hizo suya la perspectiva de los vencidos, y desde ésta "relaciones estables nunca jamás necesitan ser relaciones agradables y ya antes de la guerra hubo estratos para los que las relaciones estables fueron la miseria estable $^{\text {"171 }}$.

Parece que Donoso y Benjamin comparten -si se me permite la expresión- sintaxis y se oponen en semántica. Lo que es también biográficamente visible, pues ambos vivieron su «momento de peligro", que les impidió pensar la historia en términos de progreso y que cada uno percibió como catástrofe total. Dice Donoso: «Estamos tocando con nuestras manos la mayor catástrofe de la Historia"72, que es la derrota del orden revelado por Dios.

68 Donoso II, 272.

Donoso I, 935.

70 Benjamin I/2, 697.

71 Benjamin IV/2, 926 .

72 Donoso II, 346. 
Benjamin ve en la de la izquierda no sólo la de una estrategia política, sino la de toda una cultura que no había sabido pensar el fascismo.

De la visión de la catástrofe como regla resultan o la desesperación o, como en Donoso, una filosofía providencialista de la Historia (el mal triunfa naturalmente y sólo lo interrumpe una decisión soberana, personal y directa de Dios, o, como en Benjamin, un providencialismo profano en la desesperación, pues «sólo por los desesperados nos es dada la esperanza "73). Ambos providencialismos (el de la encarnación y el de la espera) remiten al Juicio Final ${ }^{74}$, estado de excepción por excelencia. Para Donoso, «el juicio final, en el cual el bien triunfará del mal para siempre, es como la coronación de todos los milagros"75. El Juicio Final de Benjamin es, en cambio, profano, está aquí, en el Jetztzeit de la humanidad salvada. Se trata de la alegorización de la Historia que recupera a los muertos «en una citación à l'ordre du jour: este día es precisamente el día del Juicio Final" ${ }^{176}$.

El Juicio Final es la representación más intensa del estado de excepción en ambas alternativas (el catolicismo donosiano, el socialismo benjamininano) a la barbarie. El estado de excepción hace justicia. Esta es, en Donoso, el «Orden establecido por Dios en el principio"77. Políticamente, sirve al orden. En Benjamin, por el contrario, es una salida del orden. Tal era la tarea de un proletariado alimentado «de la imagen de los antecedentes esclavizados ${ }^{78}$ a los que había de salvar. A semejante citación del pasado llamó Benjamin «Eingedenken". «Esto es Teología -reconoció Benjamin-; pero en el «Eingedenken» hacemos una experiencia

Benjamin I/1, 201.

74 La conexión entre las ideas de "no clausura del pasado" y "Juicio Final" está en el centro de la polémica de Benjamin con Horkheimer. Benjamin II/3 1332s; V/1 588-9.

75 Donoso II, 333.

76 Benjamin I/2, 694 .

77 Donoso II, 580 .

78 Benjamin I/2, 700 . 
que nos prohibe concebir la historia como fundamentalmente ateológica, $\tan$ poco como podemos intentar escribirla en conceptos inmediatamente teológicos ${ }^{179}$.

Benjamin, judío siempre, carece de imagen de la humanidad salvada ${ }^{80}$. Conoceremos a ésta en la interrupción del continuo. Lo que nos devuelve al lado de Sorel si entendemos la huelga general como suspensión del Derecho. No se ha prestado atención suficiente a lo que las tesis de Benjamin deben a las «Reflexiones sobre la violencia» de Sorel. Pues la huelga general cumple en una «teología política de la espera» funciones equivalentes a la dictadura en una «teología política de la encarnación", ya que en ella coinciden dos esperanzas: La de interrupción de la continuidad jurídica y la de realización de la justicia.

Benjamin entendió mejor que nadie el significado del «estado de excepción» schmittiano. Vio que el fascismo no era interrupción, sino continuidad en el capitalismo $0^{81}$. Su insatisfacción ante el aparato de Derecho es opuesta a la de Schmitt. Por eso le interesa tanto la singularidad jurídica que Sorel desvela en el derecho de huelga. Pues, en virtud de ésta, «la clase obrera organizada es hoy, junto con los estados, el único sujeto que tiene derecho a la violen$\mathrm{Cia}^{182}$. La huelga general proletaria supone lo contrario que la dictadura, ya que, opuesta a todo reformismo, «se plantea como único objetivo la destrucción del poder del Estado", a ojos de Sorel, "razón de ser de los grupos dominantes" ${ }^{13}$.

Más allá del proyecto anarquista de Sorel, Benjamin desearía otro orden que tuviese en cuenta las víctimas del pasado. «Puesto

\footnotetext{
79 Benjamin V/1, 589.

80 Benjamin I/3, 1232 .

81 Benjamin III, 444.

${ }^{82}$ Benjamin II/1, 183. Utilizo la versión castellana que de "Zur Kritik der Gewalt" aparece en: Walter Benjamin, Angelus Novus, Barcelona 1971.

${ }_{83}$ Benjamin II/1, 194. London imaginó los padecimientos de esos grupos dominantes en un San Francisco ganado por la huelga general. En el relato de London, los burgueses no aciertan a calificar una parálisis que los obreros viven como fiesta: ¿sedición?, ¿revolución?, ¿anarquía? Jack London, La huelga general, Madrid 1991, p. 14.
} 
que toda forma de concebir una solución de las tareas humanas - para no hablar de un rescate de la esclavitud de todas las condiciones históricas de vida pasadas- resulta irrealizable si se excluye absolutamente y por principio toda y cualquier violencia, se plantea el problema de la existencia de otras formas de violencia que no sean la que toma en consideración toda teoría jurídica"84. La violencia revolucionaria fundaría una nueva época histórica «sobre la destitución del derecho junto con las fuerzas en las cuales se apoya, al igual que ellas en él, es decir, en definitiva, del Estado"85. Ese es el milagro en Benjamin: la violencia revolucionaria.

El doble rostro del «estado de excepción» tiene su reflejo en la historia de la bandera roja. Sorel la refiere así: «Esa enseña se utilizaba, en tiempos de disturbios, para avisar que se iba a aplicar la ley marcial; el 10 de agosto de 1792, se transformó en símbolo revolucionario, con miras a proclamar «la ley marcial del pueblo contra los rebeldes del poder ejecutivo"86. Si Schmitt juzgó al pueblo sólo capaz del sí o del no ${ }^{87}$, Benjamin creyó en una clase que, como el dictador decisionista, reconociese y aprovechase su oportunidad: la decisión que interrumpe el vuelo del ángel coincide con la mirada que reconoce el presente mencionado en el pasado. Su éxito sería lo portentoso posible. Pues «ya sólo queda, en la esperanza permanente del asalto final, dirigir la mirada hacia lo único que aún puede aportar salvación: lo extraordinario. Pero ese estado de atención extrema y resignada que la situación exige, podría, ya que mantenemos un misterioso contacto con las fuerzas que nos asedian, provocar realmente el milagro" ${ }^{\prime 18}$. Lo demás es

\footnotetext{
84 Benjamin II/ $1,196$.

85 Benjamin II/1, 202.

86 Sorel, Réflexions sur la violence (Nota 51) p. 255.

87 Carl Schmitt, Verfassungsiehre, München und Leipzig 1928, p. 84.

Benjamin IV $/ 1,95$. Hay una buena traducción castellana de "Einbahnstrasse", de la que me he servido. Se debe a Juan J. del Solar y a Mercedes Allendesalazar: Walter Benjamin, Dirección única, Barcelona 1987.
} 
naturaleza, progreso, aniquilación ${ }^{89}$.

Pero tal clase, como el soberano de Donoso y a diferencia del de Schmitt, estaria sometido a un precepto metajurídico. El de Benjamin manda construir una Historia Universal no reaccionaria, es decir, aquella en que caben los muertos, mesiánica ${ }^{90}$, cuyo modelo "existe en la Historia sagrada»" El pueblo unido en la revolución tiene el aspecto de los hombres de Pallas concentrados en la construcción de una torre ${ }^{92}$. Pero el Dios de Donoso sólo consiente unidad en la cruz: «La Babel democrática tendrá la misma suerte que la Babel de los libros santos (...).

Antes que esté acabada la torre, Dios castigará a las naciones y dispersará a los pueblos $\aleph^{93}$.

«La excepción piensa lo general con enérgica pasión", recordaba Schmitt, citando a un teólogo ${ }^{94}$. Esa «excepción" se hace categoría de la identidad en Donoso, como en Benjamin de la no identidad. Medido por uno, el mundo está completo; medido por el otro, es un fragmento ${ }^{95}$. Ambos son justicia que no cabe en el Derecho. $Y$ así, la dictadura «aparece como el rayo que rasga el seno de la nube, inflama la atmósfera, hiere a la víctima y se extingue ${ }^{96}$, y la violencia revolucionaria, como el juicio de Dios «golpea sin preaviso, sin amenaza, fulmíneamente ${ }^{97}$.

id.

90 Benjamin $1 / 3,1239$.

91 Benjamin $1 / 3,1234$

92 El interés político de Benjamin por la ficción "Lesabéndio" de Scheerbart no tiene nada que ver con la política-ficción. En Scheerbart halla Benjamin la idea de una técnica que no explota ni a la naturaleza ni a los hombres. Benjamin II/2, pp. $630-632$.

93 Donoso II, 981.

94 Schmitt, Politische Theologie (Nota 4) p. 22. El teólogo no es otro que Kierkegaard, al que Schmitt llama en diferente lugar "el contemporáneo histórico de Donoso en el Norte". Carl Schmitt, Donoso Cortés in gesamteuropäischer Interpretation (Nota 41) p. 107. 140.

95 Ralf Konersmann, Walter Benjamins Begriff der Geschichte, Hagen 1989, p.

\% Donoso I, 390.

${ }^{97}$ Benjamin II/1, 199: 